\title{
An increase in IL-1 $\beta$ concentrations in embryo culture-conditioned media obtained by in vitro fertilization on day 3 is related to successful implantation
}

\author{
Karina Sequeira $^{1}$ - Aurora Espejel-Núñez ${ }^{2}$ Eva Vega-Hernández ${ }^{1}$. \\ Anayansi Molina-Hernández ${ }^{3}$ Patricia Grether-González ${ }^{4}$
}

Received: 30 June 2015 / Accepted: 7 September 2015 / Published online: 26 September 2015

(C) The Author(s) 2015. This article is published with open access at Springerlink.com

\begin{abstract}
Purpose This study aimed to evaluate interleukin (IL)-1 $\beta$ concentrations in maternal serum and in embryo-cultured conditioned media and to correlate these findings with success of implantation.

Methods A total of 70 infertile women who underwent in vitro fertilization treatment were studied. IL- $1 \beta$ concentrations were quantified in maternal serum and in embryo culture-conditioned media on days 1 and 3 . The findings were compared between those who achieved pregnancy and those who did not.

Results No significant differences were found in IL- $1 \beta$ serum concentrations between the groups. IL-1 $\beta$ was not detected in day 1 culture-conditioned medium. On day 3, IL-1 $\beta$ was quantified in 27 patients, and IL- $1 \beta$ concentrations were significantly higher in women who achieved pregnancy than in those who did not $(p<0.001)$.
\end{abstract}

Capsule High IL-1 $\beta$ concentrations in culture-conditioned medium after in vitro fertilization treatment suggest a role of embryonic IL- $1 \beta$ in the success of implantation.

Patricia Grether-González

pgrether@gmail.com

1 Department of Reproduction and Infertility, National Institute of Perinatology, Montes Urales 800 Lomas Virreyes, CP: 11000 México DF, México

2 Department of Biochemistry and Molecular Biology, National Institute of Perinatology, México DF, México

3 Department of Cell Biology, National Institute of Perinatology, México DF, México

4 Department of Human Genetics and Genomics, National Institute of Perinatology, México DF, México
Conclusions High IL-1 $\beta$ concentrations in day 3 cultureconditioned medium in patients who achieve pregnancy after in vitro fertilization treatment indicate a possible role of embryonic IL-1 $\beta$ in the implantation process.

Keywords Embryo $\cdot$ Implantation $\cdot$ Interleukin- $1 \beta \cdot$ In vitro fertilization

\section{Introduction}

The success of growth and implantation of blastocysts is a complex event that involves maternal and embryonic signals. The interleukin-1 (IL-1) system comprises the following: two agonists, IL- $1 \alpha$ and IL-1 $\beta$, an antagonist IL-1RA, and two receptors, interleukin-1 receptor type I (IL-1R tI) and interleukin-1 receptor type II (IL-1R tII) [1, 2]. This system is closely associated with implantation. In humans, IL-1R tI has been detected in the uterine endometrium from day 23 of the menstrual cycle and IL-1 $\beta$ mRNA is increased from the proliferative to the secretory phase $[3,4]$.

IL-1 $\beta$ triggers the production of IL- 8 by the endometrium, and this increases migration and survival of trophoblastic cells [5]. IL-1 $\beta$ increases secretion of prostaglandin E2 and leukemia inhibitory factor, as well as the expression of integrin $\alpha_{v} \beta_{3}$. In addition, the presence of IL- $1 \beta$ has been demonstrated in the villous cytotrophoblast, the syncytiotrophoblast, and the endometrial glands of the maternal decidua [6].

A reduction in integrin $\alpha_{v} \beta_{3}$ expression has been observed in luteal-phase deficiency, infertility of unknown cause, and in the hydrosalpinges. Interestingly, expression of this integrin is regulated by IL-1 that is secreted by embryos [7]. In the mouse, blockage of IL-1R tI with IL-1RA can in turn block implantation [8]. 
After the process of in vitro fertilization (IVF), implantation is positively correlated with high serum IL- $1 \alpha$ and IL- $1 \beta$ concentrations. The implantation rates of patients in assisted fecundation cycles are higher in women who have greater IL$1 \beta$ concentrations in blood on the day of human chorionic gonadotropin administration [9].

Barañao and colleagues [10] showed that IL-1 $\beta$ quantification in embryo culture-conditioned medium at $24 \mathrm{~h}$ of fertilization predicts the probability of pregnancy. In contrast, Seifer et al. [11] reported not having detected IL-1 $\beta$ in twoto six-cell human embryo supernatants. Another study showed that IL-1 $\beta$ mRNA expression was undetectable at the two-cell stage and was surprisingly low in the morula and blastocyst in mouse embryos [12]. De los Santos [13] demonstrated the presence of the whole IL-1 system in the embryo by means of immunohistochemistry. However, these authors were only able to find IL- $1 \beta$ secretion in the supernatant of embryos when these were co-cultured with epithelialendometrial cells during all developmental stages.

Currently, the significance of serum IL-1 $\beta$ concentrations during the IVF cycle has not yet been completely clarified. Additionally, the presence of IL- $1 \beta$ in culture-conditioned medium of embryos under development and its possible relationship with the mechanism of implantation are unclear. Therefore, this study aimed to evaluate the association of serum IL-1 $\beta$ concentrations, as well as those in embryo culture medium, with success of implantation.

\section{Materials and methods}

A prospective cohort study was carried out at the National Institute of Perinatology between April 2011 and July 2012. The study was approved by the ethics and research committees. Women younger than 40 years of age, about to undergo IVF treatment, were invited to participate. Written informed consent was obtained from all of the patients who were enrolled in the study.

We collected two 3-mL samples of peripheral blood. The first sample was collected on day 1 of the cycle when the patient's basal hormone values were quantified. The second sample was collected on the day that two follicles $>18 \mathrm{~mm}$ were observed, immediately prior to the injection of chorionic gonadotropin (last day of hormone stimulation).

Controlled ovarian hyperstimulation was initiated on day 2 of the menstrual cycle, using two alternative schemes: (1) recombinant human follicle-stimulating hormone (Gonal-F; Merck Serono, Germany) or (2) recombinant human folliclestimulating hormone and urinary menotropins (Merapur; Ferring Pharmaceuticals, Switzerland). The ovarian stimulation protocol was selected by each treating physician as follows: (1) a long standard protocol with a gonadotropinreleasing agonist (Lucrin; Abbott, USA) in only six patients or (2) a flexible antagonist protocol (Cetrotide; Merck Serono, Germany) in 58 patients. No patients were transferred when estradiol levels were greater than $3500 \mathrm{pg} / \mathrm{ml}$ or progesterone levels were greater than $0.15 \mathrm{ng} / \mathrm{ml}$.

For IL-1 $\beta$ quantification in serum, peripheral blood was centrifuged at $3000 \mathrm{rpm}$ for $5 \mathrm{~min}$. The serum was collected and frozen at $-70{ }^{\circ} \mathrm{C}$ for later processing.

The oocytes were analyzed in the Assisted Reproduction Laboratory to define their morphological state and were incubated for approximately $4 \mathrm{~h}$ prior to fertilization. Standard IVF and intracytoplasmic sperm injection were performed. After fertilization, the zygotes were cultured in G-1TM/G-1TM PLuS medium (Vitrolife, San Diego CA, USA). The culture media were recovered at 24 and $72 \mathrm{~h}$ after fertilization. On day 3 prior to embryo transfer, we carried out morphological evaluation of the embryos using the Lucinda Veeck classification [14]. The embryos were categorized based on morphological evaluation into three groups: only top (qualities 1,2 according to Lucinda Veeck classification), top and non-top (qualities 1, 2, 3, 4), and only non-top (qualities 3, 4).

Each embryo was cultured separately, but samples were the result of a pooled medium culture of two or three embryos. Culture media were mixed because we needed a minimum of $15 \mu \mathrm{L}$ for testing. Therefore, those patients who achieved a unique embryo and patients who failed to be transferred were excluded $(n=6)$. We included only patients with two or three transferred embryos. These samples were immediately frozen at $-70{ }^{\circ} \mathrm{C}$ for later processing.

IL-1 $\beta$ concentrations were quantified by the enzymelinked immunosorbent assay technique (cat. DY401; R\&D Systems, USA) using $100 \mu \mathrm{L}$ of serum or the total volume of the embryo medium culture mixture. A standard curve of $1.5-50 \mathrm{pg} / \mathrm{mL}$ with a sensitivity limit of $0.1 \mathrm{pg} / \mathrm{mL}$ was used to calculate IL- $1 \beta$ concentrations. Inter- and intra-assay coefficients of variation were $<10 \%$. An absorbance reading was taken at $450 \mathrm{~nm}$ (Synergy ${ }^{\mathrm{TM}}$ HT; BioTek Instruments, Winooski, VT, USA).

Pregnancy or successful implantation was considered in patients who were positive for beta human chorionic gonadotropin $(1 \mathrm{mIU} / \mathrm{ml}) 14$ days post-transfer of embryos.

The results are expressed as mean \pm standard error of the mean. Differences between groups were compared by the Mann-Whitney $U$ test. Significant differences were considered as $p<0.05$.

\section{Results}

\section{Patients}

The total number of patients studied was 64 . All of the patients were Mexicans with a mean age of $34 \pm 3$ years. The threshold 
Table 1 Baseline characteristics of patients included in the study

\begin{tabular}{|c|c|c|c|c|c|}
\hline & $\begin{array}{l}\text { Pregnancy } \\
n=29\end{array}$ & $\begin{array}{l}\text { No pregnancy } \\
n=35\end{array}$ & $U$ & $Z$ & $p$ \\
\hline Age (years): median (min-max) & $34(22-28)$ & $34(27-39)$ & 493 & -0.91 & 0.42 \\
\hline BMI $\left(\mathrm{kg} / \mathrm{m}^{2}\right)$ : median (min-max) & $24.6(17-32)$ & $24.3(17-29)$ & 484 & -0.31 & 0.37 \\
\hline Years of infertility: median (min-max) & $5(1-8)$ & $7(3-8)$ & 427 & -1.08 & 0.13 \\
\hline Follicles $>18$ mm: median (min-max) & $7(3-14)$ & $5(3-18)$ & 466 & -0.56 & 0.28 \\
\hline Estradiol (pg/ml) the day of hCG median (min-max) & $1386(1109-2548)$ & $1633(820-3394)$ & 495 & -0.16 & 0.43 \\
\hline Number or embryos transferred: & & & 485 & -0.39 & 0.34 \\
\hline $2: n(\%)$ & $7(24.1)$ & $10(28.6)$ & & & \\
\hline $3: n(\%)$ & $22(75.9)$ & $25(71.4)$ & & & \\
\hline Quality of transfer embryos: & & & 395 & -1.81 & 0.79 \\
\hline Only top (quality 1,2$): n(\%)$ & $22(75.9)$ & $20(57.1)$ & & & \\
\hline Top and non-top (quality $1,2,3,4): n(\%)$ & $7(24.1)$ & $10(28.6)$ & & & \\
\hline Only non-top (quality 3,4$): n(\%)$ & $0(0.0)$ & $5(14.3)$ & & & \\
\hline
\end{tabular}

Mann-Whitney $U$ test. $B M I$ body mass index, $h C G$ human chorionic gonadotropin. No significant differences were found between the two groups

estradiol level on the day of human chorionic gonadotropin administration was $1582 \pm 550 \mathrm{pg} / \mathrm{ml}$. No correlation between the quantification of IL- $1 \beta$ and serum estradiol $(p=0.39)$ was found. The baseline characteristics of the patients are shown in Table 1. The group of women who achieved pregnancy was compared with the group of women who failed to do so. There were no significant differences in baseline characteristics between the two groups.

Standard IVF was performed in $44(68.8 \%)$ patients and intracytoplasmic sperm injection in 20 (31.3\%). The study participants were divided into two groups: 29 patients had a successful implantation or pregnancy and 35 patients did not achieve pregnancy. In the group of patients who failed to get pregnant, a total of 80 embryos were transferred, while in the group that achieved pregnancy, 95 embryos were transferred.

\section{Quantification of IL-1 $\beta$ concentrations in maternal serum}

Serum quantification of IL- $1 \beta$ at initiation of treatment on day 1 was $0 \mathrm{pg} / \mathrm{mL}$ in $96.8 \%(n=62)$ of patients. In serum samples from the last day of controlled ovarian hyperstimulation, 47 patients $(73 \%)$ had detectable IL- $1 \beta$ concentrations, with a mean concentration of $39.5 \pm 10.3 \mathrm{pg} / \mathrm{mL}$. No difference in IL$1 \beta$ concentrations was found between patients who achieved pregnancy and those that failed to do so $(52.7 \pm 22.0$ vs. $28.7 \pm$ $5.2 \mathrm{pg} / \mathrm{mL} ; p=0.29$ ).
Fig. 1 Box and whisker plot shows IL- $1 \beta$ concentrations in embryo culture medium at day 3 and their relation to successful implantation. No pregnancy, $n=$ 35; pregnancy, $n=29$. The results are expressed as mean \pm standard error of the mean. Boxes represent the median, and the 25th and 75th percentiles. Asterisk indicates a significant difference $(p<0.001)$ between the two groups of IVF patients

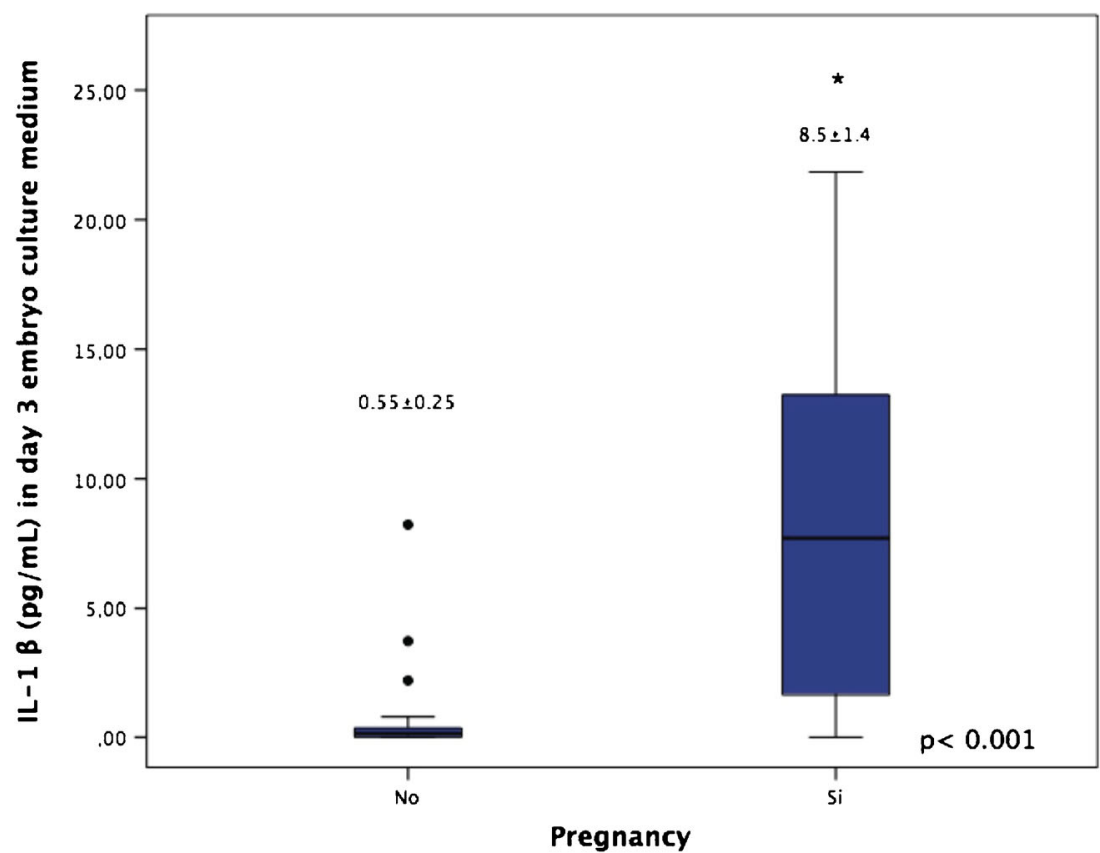




\section{Quantification of IL-1 $\beta$ concentrations in embryo culture-conditioned medium}

On day 1 post-fertilization, we did not detect IL- $1 \beta$ concentrations $(0 \mathrm{pg} / \mathrm{mL}$ in 64 patients). The percentage of detection of IL- $1 \beta$ concentrations on day 3 of embryo development was $42 \%$ (27 patients), with a mean concentration of $4.1 \pm 0.82 \mathrm{pg} /$ $\mathrm{mL}$.

We found that IL-1 $\beta$ concentrations of embryo supernatants of patients who achieved pregnancy were significantly higher than those in patients who did not achieve pregnancy ( $8.5 \pm 1.4$ vs. $0.55 \pm 0.25 \mathrm{pg} / \mathrm{mL} ; p<0.001$; Fig. 1 ).

\section{Discussion}

One of the major issues in IVF is why patients who are submitted to repeated cycles of IVF with transfer of apparently good-quality embryos do not achieve pregnancy. This inexplicable failure in implantation is the basis of the current study.

Our study failed to detect any significant differences in serum IL-1 $\beta$ concentrations after stimulation of hormones. Karagouni et al. [9] detected serum IL-1 $\beta$ concentrations in $58 \%$ of 33 patients with post-hCG concentrations of $68.5 \pm$ $24.6 \mathrm{pg} / \mathrm{mL}$ in pregnant women and $20.5 \pm 13.4 \mathrm{pg} / \mathrm{mL}$ in women without pregnancy. The reason for this difference between studies could be because hCG stimulates IL- $1 \beta$ secretion. In the present study, IL- $1 \beta$ was quantified after hormonal stimulation and prior to hCG administration to determine if elevation of IL- $1 \beta$ could have been related to the administration of FSH/MHG alone. Our findings indicated that controlled ovarian hyperstimulation induces systemic production of IL-1 $\beta$. Therefore, IL-1 $\beta$ may have a regulatory effect on previous administration of hCG.

Our study showed IL-1 $\beta$ concentrations in embryo medium culture on day 3 of development and their correlation with pregnancy. Previous studies have suggested that embryos are not capable of secreting IL-1 $\beta$ if they are not co-cultured with endothelial cells. However, we were able to detect IL-1 $\beta$ in embryo medium culture at 3 days of development (eight cells) [13].

Notably, even though we did not achieve detection of IL$1 \beta$ in a high proportion of patients, those who were positive showed an association between IL-1 $\beta$ concentrations and pregnancy. This finding suggested that IL- $1 \beta$ production could play an important role in the implantation process.

Barañao et al. [10] reported IL-1 $\beta$ concentrations of $49 \pm$ $7 \mathrm{pg} / \mathrm{mL}$ in embryo culture supernatant at $24 \mathrm{~h}$, but we did not find a detectable amount of IL- $1 \beta$ on day 1 . This difference between studies may be due to the fact that we cultured single embryos per well and Barañao et al. [10] cultured a mean number of $5 \pm 1$ embryos per well. However, our finding is in agreement with that reported by Seifer et al. [11] who did not achieve quantification of IL-1 $\beta$ of two- to six-cell human embryo supernatants (on days 1 and 2). Our finding is also consistent with that reported in mice by Kruessel and colleagues, who did not find mRNA expression of IL- $1 \beta$ in the two-cell stage [12].

Four of the 37 patients who were negative for IL- $1 \beta$ in day 3 supernatants achieved pregnancy. The use of pooled media limited the level of the analysis because we quantified mean IL- $1 \beta$ production of two or three embryos and not individual IL-1 $\beta$ production. However, we consider that IL- $1 \beta$ synthesis could have started later in these embryos without impairing the implantation process.

While the IL-1 system is known to be associated with implantation, various questions with respect to its regulation still remain. Knowledge of the normal expression patterns of this cytokine can aid in predicting success in implantation, in selecting the embryos to be transferred in IVF programs, and in increasing the success of pregnancy.

Open Access This article is distributed under the terms of the Creative Commons Attribution 4.0 International License (http://creativecommons.org/licenses/by/4.0/), which permits unrestricted use, distribution, and reproduction in any medium, provided you give appropriate credit to the original author(s) and the source, provide a link to the Creative Commons license, and indicate if changes were made.

\section{References}

1. Huang HY. The cytokine network during embryo implantation. Chang Gung Med J. 2006;29:25-36.

2. Bourdiec A, Shao R, Rao CV, Akoum A. Human chorionic gonadotropin triggers angiogenesis via the modulation of endometrial stromal cell responsiveness to interleukin 1: a new possible mechanism underlying embryo implantation. Biol Reprod. 2012;87:110 .

3. Simon C, Piquette G, Frances A, Westphal LM, Heinrichs WL, Polan ML. Interleukin-1 type I receptor messenger ribonucleic acid expression in human endometrium throughout the menstrual cycle. Fertil Steril. 1993;59:791-6.

4. Pretto CM, Héloïse P, Chevronnay G, Cornet PB, Galant C, Delvaux D, et al. Production of interleukin-1 by human endometrial stromal cells is triggered during menses and dysfunctional bleeding and is induced in culture by epithelial interleukin-1 released upon ovarian steroids withdrawal. J Clin Endocrinol Metab. 2008;93: 4126-34.

5. Vassiliadis S, Relakis K, Papageorgiou A, Athanassakis I. Endometriosis and infertility: a multi-cytokine imbalance versus ovulation, fertilization and early embryo development. Clin Dev Immunol. 2005;12:125-9.

6. Hirota Y, Osuga Y, Hasegawa A, Kodama A, Tajima T, Hamasaki $\mathrm{K}$, et al. Interleukin (IL)-1 beta stimulates migration and survival of first-trimester villous cytotrophoblast cells through endometrial epithelial cell-derived IL-8. Endocrinology. 2009;150:350-6.

7. Bigonnesse F, Labelle Y, Akoum A. Triphasic expression of interleukin-1 receptor type 1 in human endometrium throughout the menstrual cycle of fertile women and women with unexplained infertility. Fertil Steril. 2001;75:79-87. 
8. Simon C, Frances A, Piquette GN, el Danasouri I, Zuarawski G, Dang W, et al. Embryonic implantation in mice is blocked by interleukin-1 receptor antagonist. Endocrinology. 1994;134:521-8.

9. Karagouni E, Chryssikopoulos A, Mantzavinos T, Kanakas N, Dotsika EN. Interleukin-1 $\beta$ and Interleukin-1alpha may affect the implantation rate of patients undergoing in vitro fertilization-embryo transfer. Fertil Steril. 1998;70:553-9.

10. Barañao R, Piazza A, Rumi L, Polak de Fired E. Interleukin-1 $\beta$ levels in human embryo culture supernatants and their predictive value for pregnancy. Early Hum Dev. 1997;48:71-80.

11. Seifer DB, Romero R, Berlinsky D, Haning Jr RV. Absence of immunoreactive cytokines in supernatants of individual preimplantation human embryos. Am J Reprod Immunol. 1993;23:105-7.
12. Kruessel JS, Huang HY, Wen Y, Kloodt AR, Bielfeld P, Polan ML. Different pattern of interleukin-1beta-(IL-1beta), interleukin-1 receptor antagonist- (IL-1ra) and interleukin-1 receptor type I- (IL-1R tI) mRNA-expression in single preimplantation mouse embryos at various developmental stages. J Reprod Immunol. 1997;34:103-20.

13. De los Santos MJ, Mercader A, Francés A, Portoles E, Remohi J, Pellicer A, et al. Role of endometrial factors in regulating secretion of component of the immunoreactive human embryonic Interleukin-1 system during embryonic development. Biol Reprod. 1996;54:563-74.

14. Veeck L. An atlas of human gametes and conceptuses. Carnforth: Parthenon Publishing; 1999. 